\title{
Civic Community Theory and Rates of Violence: A Review of Literature on an Emergent Theoretical Perspective ${ }^{1}$
}

Jessica M. Doucet, Assistant Professor

Department of Sociology

Founders Hall 244

Francis Marion University

P.O. Box 100547

Florence, South Carolina 29502

Matthew R. Lee, Professor

Department of Sociology

Room 106c, Stubbs Hall

Louisiana State University

Baton Rouge, Louisiana 70803

Corresponding author: Jessica M. Doucet: jdoucet@fmarion.edu; 0118436611802

\begin{abstract}
Civic community theory has emerged in the last 10 years as a middle range theory to explain community variation in rates of crime. It has proven to be particularly powerful for explaining variations in violent crime across rural communities in the U.S. This essay provides a review of the available published literature testing components of the theory. The three main conceptual dimensions of the civic community thesis are outlined, and the nature of the empirical evidence is evaluated. The essay concludes with several suggestions for future research.
\end{abstract}

Keywords: Civic Community Theory; Violent Crime 
Civic Community Theory and Rates of Violence: A Review of Literature on an Emergent Theoretical Perspective - Doucet and Lee

\section{Introduction}

Rural communities have long had a reputation as a laid-back, worry-free, safe haven from an urban-centric "violent" society (Frank 2003; Willits, Bealer and Timbers 1990). In rural communities, everyone knows everyone else and sleeps with the doors unlocked because bad things are not supposed to happen in small towns (Frank 2003). This reputation is bolstered by the knowledge that these areas tend to experience drastically lower crime rates than metropolitan or urban areas. However, despite the idyllic image of rural America, these communities are not free from violence. Historical research suggests that violent outcasts from more densely populated areas were the inhabitants of rural towns in early colonial America (Weisheit, Falcone, and Wells 2006). Additionally, recent research has shown that some rural communities have more crime than urban centers, and that there tends to be pockets of violence existing in rural America (Jobes, Barclay, Weinand, and Donnermeyer 2004). Regardless, violence in rural areas has been understudied due to the assumption that explanations for crime in urban America also shed light on rural crime (Weisheit et al 2006). This belief stems from the notion that rural areas are just smaller versions of urban areas with the same culture, facing the same social and economic issues (Weisheit et al 2006). As a result, much of the criminological research has focused its attention on explaining urban rates of crime and violence.

Despite these oversights, researchers have begun to understand that rural areas are contextually distinct from large cities and that these differences need to be illuminated. Extant research has revealed that rural violence is not exactly the same as urban violence. One possible distinction is the influence of culture on violence in rural areas. Nisbett and Cohen (1996) contend that violence can be partially attributed to the nomadic way of life followed by the ancestors of current residents. Herding animals was an important component to their survival. In order to protect their family and livelihood, these residents are thought to have followed a culture of honor that approves of violence in certain situations, such as affronts to one's honor (see Nisbett and Cohen 1996, among others). Additionally, the sporadic settlement of rural areas left residents isolated from others, which perpetuated the self-sufficiency typically seen among rural people (Salamon 1997). Isolation as well as a general distrust of government led residents to rely on informal (sometimes violent) means for handling offensive situations (Weisheit et al 2006). Research has found this culture of honor to be linked to higher rates of violence, particularly in rural areas where there are more white males (Ayers 1991; Nisbett and Cohen 1996).

Another aspect of rural culture is the history of patriarchal ideology. While this viewpoint used to dominate rural life, it has been waning as the landscape of America changes. Women have new roles and responsibilities that contradict the patriarchy. Rural men, however, tend to carry these attitudes and have peers who support violence against women in an attempt to uphold a diminishing patriarchal masculinity (DeKeseredy, Schwartz, Fagen, and Hall 2006; Messerschmidt 1993; Raphael 2001). Support for these ideals is found in studies of rural 
domestic violence which shows that a patriarchal ideology facilitates abuse Gagne, 1992; Websdale 1995, 1998).

Aside from culture, research has also found that assuming explanations of urban violence apply to the rural milieu is faulty. For example, poverty is well-known in the criminological literature to be related to higher urban crime rates (see Land, McCall and Cohen 1990 among others). However, the relationship within the rural context is not as obvious. Research has found conflicting results, with some studies finding the expected relationship, while others find the opposite or no relationship (Barnett and Mencken 2002; Bouffard and Muftić 2006; Li 2011; Osgood and Chambers 2000; Petee and Kowalski 1993; Wells and Weisheit 2004). In addition, one study examined the effects of the spatial concentration of poverty on violence in rural and urban communities and found that poverty concentration was related to violence only in urban counties (Lee, Maume and Ousey 2003).

The research presented is only a small portion of what has been studied regarding rural violence. It has served to draw attention to the intricacies of rural life and illustrate the importance of studying these areas in order to inform the criminological literature and to better understand violence overall. However, even though progress has been made with regard to explaining rural crime as different from urban crime, much research has focused on applying well-known urban theories, such as social disorganization theory, to the rural context.

Community level criminological research on violence has long been dominated by the social disorganization perspective (see Bursik 1988; Sampson and Groves 1989; Sampson, Raudenbush and Earls 1997; Shaw and McKay 1942). The central focus of this body of literature has been the effects of population change and socioeconomic disadvantage on rates of crime (see Land et al 1990, and the reviews in Parker, McCall and Land 1999; Peterson and Krivo 2005), although a small number of studies have focused on social networks (Browning, Feinberg and Dietz 2004; Warner and Rountree 1997). However, a new explanation for community variation in violent crime rates in the U.S. has recently emerged in civic community theory. Civic community theory grew out of the rural community development literature (Goldschmidt 1978; Mills and Ulmer, 1970) and, like the disorganization perspective, focuses on the nature of population structures and the social and economic infrastructure of communities. There are several aspects of the theory which set it apart from the stock social disorganization thesis though. These include a nearly exclusive focus on rural communities, an explicit recognition of the role of faith based organizations and activities in communities, and the incorporation of the scale of local capitalist enterprise into the theoretical framework.

A fairly substantial body of research has now been published either directly testing components of civic community theory or providing some kind of evidence consistent with the theory. This essay delineates the theoretical dimensions of the civic community perspective and the reasons why the identified social and economic dimensions should be related to lower violent 
Civic Community Theory and Rates of Violence: A Review of Literature on an Emergent Theoretical

Perspective - Doucet and Lee

crime rates. Findings from available research are then discussed and evaluated. The essay concludes with a discussion of areas for future research on the civic community-violent crime link.

\section{Conceptual Dimensions of Civic Community}

Like the social disorganization tradition, civic community theory is a macro-level social control perspective. It assumes that well-integrated communities are better positioned to regulate the behavior of their members. There are three dimensions on which the civic community literature focuses: residential stability and local investment, civic engagement and supporting institutional infrastructure, and local capitalism and the economically independent middle class.

\section{Residential Stability and Local Investment}

The first dimension of civic community theory is the residential stability of local communities, and the corollary notion of local investment. The disorganization tradition early on recognized the harmful effects of frequent population turnover within communities (see Shaw and McKay 1942). The civic community perspective takes a similar approach. Based in part on the systemic community attachment literature (see Kasarda and Janowitz 1974), length of residence within communities is believed to strengthen local social ties, increase associational and organizational participation, and overall enhance the density of acquaintanceship (see Freudenberg 1986). Some research also points to the nonrecursive nature of the civic community - residential stability relationship, in the sense that civic communities also have an abundance of mechanisms that anchor people to place (Irwin, Tolbert and Lyson 1999).

Related to this, local investment in terms of home ownership greatly elevates the stakes that individuals have in their community. A home is typically one of the largest investments people make, one that is expected to appreciate in value over time and which is significantly affected by the quality of life in the community in which it is situated. As such it is a major incentive to take concrete steps to ensure problem behaviors and serious crime do not get a foothold in the local area. High levels of residential stability coupled with widespread local investment then are typically expected to be associated with low rates of serious crime because the social control capacity of such communities in terms of deep social roots and strong incentives for prosocial community action should be well developed.

\section{Civic Engagement and Local Institutions}

Institutions such as churches and associations are thought to be linked to lower rates of violent crime because of the social ties and mutual trust they foster within communities. Institutions themselves serve as nodes of behavioral interaction where individuals meet, develop personal relationships, shared both understandings and a sense of community. Being civically engaged, whether in social or political activities, fosters social ties, builds trust within the 
community, and leads to commonly shared goals, norms and values (Lee 2008). Civic community theorists emphasize both secular and faith based institutions and engagement. Secular forms include participation in associations, informal socializing and neighboring, and voting. These activities are thought to further strengthen the network structure of communities because members are actively involved and collectively participating. By extension, when the members of such communities demonstrate high levels of participation, they are assumed to be more likely to come together when there are challenges to community well-being (Lee 2008).

A second form of engagement is through faith based organizations. Faith based institutions themselves provide an important venue through which people interact and build trust and social networks. They also support civic engagement in the sense that they become focal points of community problem solving and civic action (Pattillo-McCoy 1998). With respect to faith based organizations, it is generally asserted that there are two forms of social capital that are fostered. The first type is bridging capital, which is thought to foster ties between members of the community because members do not simply interact with those within their denomination, but are more active in the broader community. Those engaged in denominations that promote bridging activities are also highly engaged in the community and other activities outside of the religious realm. The second type of capital that can be fostered is bonding capital. This type of capital is thought to be detrimental to the community because it does not foster ties between community members, but instead fosters ties only within the organization (Beyerlein and Hipp 2005; Putnam 2000). Thus internal bonds are strong, but links to resources outside of the organization are weak and limited.

\section{Local Capitalism and the Economically Independent Middle Class}

Broadly speaking, local capitalism is also thought to be a desirable aspect of community life. Locally owned businesses are argued to be beneficial to communities because the owners of small businesses are intricately embedded in the communities in which they are located. They have a vested interest in their communities and are more likely to get out and get involved in their communities because the success of their businesses depends in part on the success of their communities (Mills and Ulmer 1970). Locally owned businesses are less likely to leave when times get tough because of their ties to the community. Proprietors of such businesses are also able to provide support, membership, and direction to other institutions in the community, further strengthening social ties and energizing the civic spirit (Tolbert, Lyson and Irwin 1998). The concept of the economically independent middle class is intimately tied to this idea; it is this group that sustains local capitalism and who exert leadership in civic affairs (Mills and Ulmer 1970), what Lyson, Torres and Welsh (2001) call the civically engaged middle class. The counter example would be large absentee owned firms or big box retailers that maintain very impersonal relationships with the community at large. Such organizations may exhibit little or no interest in the well-being of the community, and largely view it as a reservoir of cheap labor. Locally oriented capitalism has a completely different relational standing with local communities 
Civic Community Theory and Rates of Violence: A Review of Literature on an Emergent Theoretical

Perspective - Doucet and Lee

because of the high level of connectedness. Theoretically, when community leaders are so interdependent with the community at large, the social control capacity of the community should be enhanced and crime rates are expected to be lower.

In summary, residential stability and local investment, faith based and secular civic engagement, and locally oriented capitalism are thought to improve the well-being of communities, including lowering violent crime rates by strengthening ties between individuals as well as ties of individuals to the community and augmenting the ability of communities to address local social problems (Lee 2008; Lyson et al 2001; Tolbert et al 1998). The strengthening of these ties allows the community to integrate members, regulate the behavior of those members, and solve community problems more readily (Lee 2008).

\section{Empirical Support for the Civic Community Thesis}

\section{Residential Stability and Local Investment}

The empirical support for the beneficial effects of residential stability and home ownership on violent crime rates is fairly uniform. Numerous studies in both urban and rural communities find that homicide and other crime rates are moderately higher where population turnover is more intensive, and conversely, that it is lower where home ownership is more widespread - net of standard indicators of local socioeconomic health (Krivo and Peterson 2000; Lee 2008; Sampson and Groves 1989). It is notable that this is the one dimension of civic community theory that performs fairly consistently across the rural - urban continuum, suggesting that the beneficial effects of stable homeowner dominated communities are fairly impervious to contextual idiosyncrasies.

\section{Civic Engagement and Local Institutions}

A growing body of empirical evidence has evolved favoring the idea that local noneconomic institutions and the concomitant levels of civic engagement are associated with lower community levels of violent crime (Beyerlein and Hipp 2005; Lee 2008; Lee and Bartkowski 2004a; Lyson et al 2001; Rosenfeld, Messner and Baumer 2001). Considering first institutions, Lee (2008) reports that the availability of churches in rural communities is associated with lower violent crime rates, while Lee and Bartkowski (2004a) find that an index of social and civic organizations and voter turnout is associated with lower levels of adult murder. Alternatively, they also find that an index of churches per capita and what they call civically engaged religious denominations is associated with lower levels of both juvenile and adult murder.

This latter point is important because other studies have also examined the protective effects of faith based civic engagement on communities. Specifically, studies have shown that civic participation through religiously engaged denominations reduces violent crime rates, or 
conversely, that communities with a proliferation of non civically engaged denominations have higher violent crime rates (Beyerlein and Hipp 2005; Ellison, Burr and McCall 2003; Lee and Bartkowski 2004b). Lee and Bartkowski (2004b) tested the effect of civically engaged denominations on juvenile homicide in 1,440 rural and 449 urban counties. To measure civically engaged denominations they used a measure derived from Tolbert et al. (1998) which classified denominations as civically engaged or not based on GSS data. They found that in rural counties where the proportion of civically engaged adherents was higher, rates of juvenile homicide were lower. However, this finding was not supported with regard to urban counties. To further test their findings, the authors disaggregated the homicide rates by victim and offender relationship. After doing this, it was found that adhering to civically engaged denominations reduced juvenile family homicide, but did not reduce rates of stranger or acquaintance homicide in rural counties. Additionally, the relationship was still not found in urban counties. The authors concluded that participation in civically engaged religious denominations had an "umbrella" effect, which protected those persons most closely linked to them. However, this participation did not have a "canopy" effect because the relationship did not extend out to those less well known by potential offenders (Lee and Bartkowski 2004b).

Parallel support for the effect of civically engaged religious denominations is found in the work by Beyerlein and Hipp (2005). In their study of 3,157 counties in the U.S., they looked at the effect of bridging and bonding social capital on rates of murder, aggravated assault and robbery (together), and burglary. They expected that bridging capital would have crime reducing effects for the reasons discussed earlier. These religious denominations foster ties between community members, not just between members of their denomination. Bonding capital, on the other hand, was expected to have detrimental effects for the community because it does not foster ties between community members but instead focuses on in-group ties. To measure bridging capital, the authors used the proportion of persons in the county that adhere to mainline Protestantism. They also measured the proportion of persons in the county that adhere to Catholicism as a second measure of bridging capital. Bonding capital was measured by the proportion of persons in a county that adhere to conservative or Evangelical Protestantism, an overall classification scheme that is consistent with the work of Tolbert et al. (1998) and Ellison et al. (2003). They found that bridging capital reduced rates of each of the types of crime measured. However, bonding capital did not have this effect on crime rates. To test the robustness of their findings, they replaced the measure of adherents with a measure of the number of congregations per 100,000 people in a county for each religious denomination, which they called institutional processes. Again, their findings were replicated showing that bridging capital reduced rates of crime. Bonding capital, on the other hand, generally did not have an effect on crime rates. The only crime bonding capital seemed to have an effect on, when measured through the number of congregations, was murder. Additionally, the authors replaced the religious measures with those of other forms of civic engagement, voting and organizational associations in particular, and found that the relationship of bridging and bonding capital remained. It can be concluded, therefore, that these studies support civic community theory and 
Civic Community Theory and Rates of Violence: A Review of Literature on an Emergent Theoretical

Perspective - Doucet and Lee

the idea that participation in religious denominations can have a dampening effect on violent crime rates in an area.

With regard to other forms of civic engagement, Rosenfeld et al. (2001) looked at the effect of voting and Elks membership in 99 primary sampling units used in the General Social Survey. They found that regardless of demographic characteristics of the area, rates of violent crime were lower where social trust was high and civic engagement was widespread. These findings are also supported in the work of Lee (2008). In his study of 1,038 nonmetro counties, he found that civic engagement, measured through religious adherence, civic associations, and voting, was negative and significantly related to violent crime rates. These studies, therefore, show that civic engagement, measured in terms of either secular or faith based forms, is important in lowering crime rates.

\section{Local Capitalism and an Economically Independent Middle Class}

Support for the importance of locally owned businesses to the well-being of the community in general, and to crime rates in particular, has also been found in recent literature (Lee 2008; Lee and Ousey 2001; Lyson et al 2001; Tolbert et al 1998). In one study, Tolbert et al. (1998) found that one manifestation of local capitalism, small manufacturing firms, increases the wellbeing of communities by reducing poverty and inequality. Lyson et al. (2001) expanded the idea of well-being to include rates of violent crime in an area. In their study of agriculturally dependent counties in the U.S., the authors found that in those counties with large farms, there were higher rates of violent crime. However, in those areas with an economically independent middle class, rates of violent crime were lower. Additionally, it was found that crime tended to decline over time in those areas with an economically independent middle class, but did not do so in those areas with large farms.

Extending the work on small manufacturing firms, Lee and Ousey (2001) found that the presence of these firms in 1,731 rural counties was directly associated with lower rates of serious crime, and that small manufacturing firms strongly interacted with socioeconomic disadvantage, buffering its impact on serious crime. Finally, Lee (2008) tested the effect of local capitalism and the presence of an economically independent middle class on violent crime rates in 1,038 rural counties. He measured this with an index of the percentage self employed, the percentage working at home, the prevalence of family owned farms, and the prevalence of small manufacturing firms. In his study, it was found that those counties that scored high on the measure of local capitalism and an economically independent middle class had lower violent crime rates than those areas that scored low on that measure. It can reasonably be concluded therefore, that a robust ethic of local capitalism and a strong economically independent middle class is associated with lower community crime rates, which also supports the basic tenets of civic community theory.

\section{Implications and Research Horizons}


While civic community theory shares many concepts with social disorganization theory, it is in many ways distinct from the disorganization perspective. There are several reasons why this is the case. First, because of its origins in the rural community development literature, civic community theory is typically more flexible in the unit of analysis than social disorganization theory. Disorganization is really an urban neighborhood theory, but rural communities do not typically conform to the standard urban neighborhood 'grid' layout. Thus, alternative units of analysis that reasonably approximate the measurement of communities in rural areas are typically employed, such as counties or small towns (see Tolbert, Irwin, Lyson and Nucci 2002). A second reason is that social disorganization theory treats different realms of social life separately as though they do not interact or impact one another. Civic community theory, on the other hand, believes that social, political, economic, and religious realms cannot be viewed separately because each affects the other. Hence its strong emphasis on faith based community factors in addition to secular community institutions and participation. Third, civic community theory recognizes that the nature of local economic organization may strongly impact the organizational capacity of local communities. Specifically, it asserts that locally oriented firms and businesses are much better for the welfare of local communities than large absentee owned firms or multinational corporations. Finally, while social disorganization theory only focuses on what holds the community together, civic community theory goes beyond this by also looking at what buffers the community from external forces (Lee 2008). For these reasons, civic community theory should be seen as separate from social disorganization theory although the two theories do share some common concepts.

Civic community theory has a number of advantages specifically for the rural context as well. One fairly consistent finding in the empirical rural crime literature is that measures of economic disadvantage from social disorganization theory do not perform as expected in the rural milieu. Low socioeconomic status, one of the main structural variables of classic social disorganization theory by Shaw and McKay (1942), is thought to be positive and significantly related to crime. However, several researchers have failed to find a statistically significant association between measures of low socioeconomic status and violence in rural areas (Lee et al 2003; Li 2011; Osgood and Chambers 2000; Petee and Kowalski 1993). Even more unexpected is the negative relationship between poverty and rape, robbery, and assault in rural areas found by Bouffard and Muftić (2006), which indicates that higher levels of poverty actually reduce these crimes. However, noneconomic indicators of social disorganization theory have been found to perform fairly consistently in the rural context (Bouffard and Muftić 2006; Lee et al 2003; Li 2011; Osgood and Chambers 2000; Wells and Weisheit 2004).

While research regarding social disorganization and rural crime is somewhat mixed, none of it is based on a test of the complete theory, which states that disorganization mediates the effects of structural measures on crime. These studies instead infer that the theory works the same in rural areas without actually testing the relationships. 


\section{Civic Community Theory and Rates of Violence: A Review of Literature on an Emergent Theoretical}

Perspective - Doucet and Lee

Kaylen and Pridemore's (2012) publication presents findings from a test of the full social disorganization model as explicated by Sampson and Groves (1989). Their findings suggest that the mediating effects surmised by social disorganization theory are not found in the rural context. These new findings, combined with prior research, suggest that the nature of social organization in rural areas may differ from urban areas. Instead of organization being influenced by the structural antecedents identified in social disorganization theory, rural organization may be more dependent on the community institutions that affect members' ties (Kaylen and Pridemore 2012). Civic community theory reveals these effects by measuring the degree of local capitalism, civic engagement, and local investment, which serve as proxies for the presence of social institutions as well as residents' connections to the community. This perspective is therefore more beneficial in theorizing about rural crime because its components capture the strength and density of social networks that appear to be more useful in explaining rural violence, or the lack thereof, than standard measures of social disorganization.

Based on this review, there are several evident directions for additional research. First, extant research, with few exceptions, has focused on the associations between various measures of civic community and violent crime rates. But in fact, the large majority of all officially recorded crime is against property. It can be argued that if the social ties so central to the theory are fostered between community members and the community is better off (in terms of lower rates of poverty, inequality, and unemployment), the reasons for committing property crimes, which are mainly instrumental, should be reduced. Some support for the effects of religious adherence on property crimes was found in the study by Beyerlein and Hipp (2005) where they found that bridging capital reduced burglary rates in a county. Future research, therefore, should focus more comprehensively on the explanatory scope of civic community theory by applying it to property crime.

Second, given that the civic community perspective emerged from the rural community development paradigm, it should come as no surprise that most of the research testing the theory focuses on rural areas, and that the studies which do try to apply the central theoretical dimensions to urban samples do not find as much support for the theory. This may be because those living in urban areas typically live in less residentially stable environments. With neighbors changing constantly, residents are less likely to come together because they do not know each other, making them less invested in the larger community or the well-being of their neighbors. This, however, does not mean that there is no civic participation in urban areas. While there is some civic engagement occurring in urban areas, membership in these organizations or associations may not be high enough relative to the total population to have a positive impact on the community. Additionally, although local capitalism may be important in these areas, urban areas may have more large firms relative to locally owned businesses. Furthermore, any locally owned businesses may not have a protective effect because local business owners do not necessarily have to have a vested interest in the community in which they are located. The sheer volume of persons in the area may be enough to keep the business afloat, unlike in rural areas 
International Journal of Rural Criminology, Volume 2, Issue 2 (June), 2014

where there are fewer possible patrons. The civic community perspective with regard to urban areas may thus require the use of smaller units of analysis to capture the anticipated effects in

those areas. Further research should be conducted to determine the nature and extent, if any, of the applicability of the civic community perspective to urban areas.

\section{Endnotes}

We appreciate questions from Troy Blanchard as a stimulus for this essay and comments from William B. Bankston and Edward Shihadeh on an earlier draft. 
Civic Community Theory and Rates of Violence: A Review of Literature on an Emergent Theoretical Perspective - Doucet and Lee

\section{References}

Ayers, E. L. (1991). Legacy of violence. American Heritage, 42, 102-110.

Barnett, C. \& Mencken, F. C. (2002). Social disorganization theory and the contextual nature of crime in nonmetropolitan counties. Rural Sociology, 67, 372-393.

Beyerlein, K. \& Hipp, J. R. (2005). Social capital, too much of a good thing? American religious traditions and community crime. Social Forces, 84, 995-1013.

Bouffard, L. A. \& Muftić, L. R. (2006). The "rural mystique": Social disorganization and violence beyond urban communities. Western Criminology Review, 7, 56-66.

Browning, C. R., Feinberg, S. L., \& Dietz, R. D. (2004). The paradox of social organization: Networks, collective efficacy, and violent crime in urban neighborhoods. Social Forces, 83, 503-534.

Bursik, R. J. (1988). Social disorganization and theories of crime and delinquency: Problems and prospects. Criminology, 26, 519-552.

DeKeseredy, W. S., Schwartz, M. D., Fagen, D., \& Hall, M. (2006). Separation/divorce sexual assault: The contribution of male peer support. Feminist Criminology, 1, 228-250.

Ellison, C. G., Burr, J. A., \& McCall, P. L. (2003). The enduring puzzle of southern homicide: Is regional religious culture the missing piece? Homicide Studies, 7, 326-352.

Frank, R. (2003). When bad things happen in good places: Pastoralism in big-city newspaper coverage of small-town violence. Rural Sociology, 68, 207-230.

Freudenberg, W. R. (1986). The density of acquaintanceship: An overlooked variable in community research. American Journal of Sociology, 92, 27-63.

Gagne, P. L. (1992). Appalachian women: Violence and social control. Journal of Contemporary Ethnography, 20, 387-415.

Goldschmidt, W. (1978). As You Sow: Three Studies in the Social Consequences of Agribusiness. Montclair, NJ: Allanheld, Osmun, and Co.

Irwin, M., Tolbert, C. M., \& Lyson, T. A. (1999). There's no place like home: Non-migration and civic engagement. Environment and Planning A, 31, 2223-2238.

Jobes, P. C., Barclay, E., Weinand, H., \& Donnermeyer, J. F. (2004). A structural analysis of social disorganization and crime in rural communities in Australia. The Australian and New Zealand Journal of Criminology, 37, 114-140. 
Kasarda, J. D. \& Janowitz, M. (1974). Community attachment in mass society. American Sociological Review, 39, 328-39.

Kaylen, M. T. \& Pridemore, W. A. (2012). Systematically addressing inconsistencies in the rural social disorganization and crime literature. International Journal of Rural Criminology, 1, 134-152.

Krivo, L. J. \& Peterson, R. D. (2000). The structural context of homicide: Accounting for racial differences in process. American Sociological Review, 65, 547-559.

Land, K. C., McCall, P. L., \& Cohen, L. E. (1990). Structural covariates of homicide rates: Are there any invariances across time and social space? American Journal of Sociology, 95, 922-963.

Lee, M. R. (2008). Civic community in the hinterland: Toward a theory of rural social structure and violence. Criminology, 46, 447-478.

Lee, M. R. \& Bartkowski, J. P. (2004a). Civic participation, regional subcultures, and violence: The differential effects of secular and religious participation on adult and juvenile homicide. Homicide Studies, 8, 5-39.

Lee, M. R. \& Bartkowski, J. P. (2004b). Love thy neighbor? Moral communities, civic engagement, and juvenile homicide in rural areas. Social Forces, 82, 1001-1035.

Lee, M. R., Maume, M. O., \& Ousey, G. C. (2003). Social isolation and lethal violence across the metro/nonmetro divide: The effects of socioeconomic disadvantage and poverty concentration on homicide. Rural Sociology, 68, 107-181.

Lee, M. R. \& Ousey, G. (2001). Size matters: Examining the link between small manufacturing, socioeconomic deprivation, and crime rates in nonmetropolitan communities. The Sociological Quarterly, 42, 581-602.

Li, Y. (2011). Social structure and informal social control in rural communities. International Journal of Rural Criminology, 1, 63-88.

Lyson, T. A., Torres, R. J., \& Welsh, R. (2001). Scale of agricultural production, civic engagement, and community welfare. Social Forces, 80, 311-327.

Messerschmidt, J. W. (1993). Masculinities and Crime: Critique and Reconceptualization. Lanham, MD: Roman and Littlefield.

Mills, C. W. \& Ulmer, M. (1970). Small business and civic welfare. In M. Aiken \& P. Mott (eds.), The Structure of Community Power (pp. 124-154). New York: Random House. 
Civic Community Theory and Rates of Violence: A Review of Literature on an Emergent Theoretical Perspective - Doucet and Lee

Nisbett, R. E. \& Cohen, D. (1996). Culture of Honor: The Psychology of Violence in the South. Boulder, CO: Westview Press.

Osgood, D. W. \& Chambers, J. M. (2000). Social disorganization outside the metropolis: An analysis of rural youth violence. Criminology, 38, 81-115.

Parker, K. F., McCall, P. L., \& Land, K. C. (1999). Determining social structural predictors of homicide: Units of analysis and related methodological concerns. In M.D. Smith \& M.A. Zahn (eds.), Homicide: A Sourcebook of Social Research (pp.107-124). Thousand Oaks, CA: Sage.

Pattillo-McCoy, M. (1998). Church culture as a strategy of action in the black community. American Sociological Review, 63, 767-784.

Petee, T. A. \& Kowalski, G. S. (1993). Modeling rural violent crime rates: A test of social disorganization theory. Sociological Focus, 26, 237-289.

Peterson, R. D. \& Krivo, L. J. (2005). Macro-structural analyses of race, ethnicity, and violence crime: Recent lessons and new directions for research. Annual Review of Sociology, 31, 331-356.

Putnam, R. D. (2000). Bowling Alone: The Collapse and Revival of American Community. New York: Simon \& Schuster.

Raphael, J. (2001). Public housing and domestic violence. Violence Against Women, 7, 699-706.

Rosenfeld, R., Messner, S. F., \& Baumer, E. P. (2001). Social capital and homicide. Social Forces, 80, 283-310.

Salamon, S. (1997). Culture. In G. A. Goreham (ed.), Encyclopedia of Rural America: The Land and People, Volume I (pp.169-172). Monsey, NY: Willow Tree Press.

Sampson, R. J. \& Groves, W. B. (1989). Community structure and crime: Testing social disorganization theory. American Journal of Sociology, 94, 774-802.

Sampson, R. J., Raudenbush, S., \& Earls, F. (1997). Neighborhoods and violent crime: A multilevel study of collective efficacy. Science, 277, 918-924.

Shaw, C. \& McKay, H. (1942). Juvenile Delinquency and Urban Areas. Chicago: University of Chicago Press.

Tolbert, C. M., Irwin, M., Lyson, T., \& Nucci, A. (2002). Civic community in small-town America. Rural Sociology, 67, 90-113. 
Tolbert, C. M., Lyson, T. M., \& Irwin, M. D. (1998). Local capitalism, civic engagement, and socioeconomic well-being. Social Forces, 77, 401-427.

Warner, B. D. \& Rountree, P. W. (1997). Local social ties in a community and crime model: Questioning the systemic nature of informal social control. Social Problems, 44, 520-536.

Websdale, N. (1995). An ethnographic assessment of the policing of domestic violence in rural Eastern Kentucky. Social Justice, 22, 102-122.

Websdale, N. (1998). Rural Women Battering and the Justice System: An Ethnography. Thousand Oaks, CA: Sage.

Weisheit, R. A., Falcone, D. N., \& Wells, L. E. (2006). Crime and Policing in Rural and SmallTown America. Long Grove, IL: Waveland Press.

Wells, L. E. \& Weisheit, R. A. (2004). Patterns of rural and urban crimes: A county-level comparison. Criminal Justice Review, 29, 1-22.

Willits, F. K., Bealer, R. C., \& Timbers, V. L. (1990). Popular images of "rurality": Data from a Pennsylvania survey. Rural Sociology, 55, 559-578. 